\title{
Retained intravitreal lens fragments after phacoemulsification: a clinicopathological correlation
}

\author{
L M W Yeo, D G Charteris, C Bunce, P J Luthert, Z J Gregor
}

\begin{abstract}
Aims-To explore the relation between clinical course and timing of vitrectomy with the nature and intensity of intraocular inflammatory response in eyes with retained intravitreal lens fragments following complicated phacoemulsification. Methods-Prospective evaluation of 22 eyes with retained lens fragments with emphasis on corneal clarity, uveitis, intraocular pressure (IOP), timing of vitrectomy, and visual outcome. Numbers of different types of inflammatory cells in vitreous washings were counted, masked to clinical details, in three nonoverlapping adjacent high power fields. Relations between clinical and pathological findings were assessed.

Results-The IOP was raised in 19 eyes before vitrectomy and remained high in nine postoperatively. The latter had higher median total cell count (104 cells/ $\mathbf{m m}^{2}$ ) than those with normal postoperative IOP ( 37 cells $\left./ \mathrm{mm}^{2}\right)$ but this difference was not statistically significantly different $(p=0.17)$. Nine of 22 eyes underwent vitrectomy within 1 week of cataract surgery. Median total cell count in these eyes was 20 cells $/ \mathrm{mm}^{2}$ compared with 140 cells $/ \mathrm{mm}^{2}$ in eyes vitrectomised later-this difference was statistically significant ( $p$ $<0.001$ ). Final visual acuity was $6 / 12$ or better in 13 eyes, these had fewer intravitreal inflammatory cells than the remaining six with poor visual outcome and no pre-existing cause for this (three patients excluded $(p=0.02)$. Macrophages were the predominant inflammatory cell type.

Conclusion-There was significantly less inflammatory cell activity in eyes which had retained lens fragments removed early (within 1 week). Later removal was associated with persistently elevated IOP and poorer visual outcome.

(Br F Ophthalmol 1999;83:1135-1138)
\end{abstract}

Dislocation of fragments of lens material into the vitreous cavity during cataract surgery by phacoemulsification is a potentially serious, sight threatening complication. Retained intravitreal lens material has been associated with significant intraocular inflammation, ${ }^{1}$ acute and chronic glaucoma, cystoid macular oedema, retinal detachment and, ultimately, poor visual acuity. ${ }^{2-6}$ Pars plana vitrectomy has been shown to be effective in removing retained lens material, reducing uveitis and glaucoma, and improving visual acuity over preoperative levels. ${ }^{1-7}$ Timing of vitrectomy is controversial, although recent reports suggest that early intervention may be advantageous. ${ }^{56}$

There have not been any published data on the histopathological changes in eyes with retained intravitreal lens fragments following phacoemulsification although findings in lens induced uveitis and phacolytic glaucoma have been reported. ${ }^{8-10}$ These included the presence of foamy macrophages and a few lymphocytes in the aqueous and vitreous of an eye with phacolytic glaucoma. ${ }^{9}$

The aim of this study was to analyse the cellular response in eyes after phacoemulsification complicated by retained intravitreal lens fragments and to assess association between the nature and intensity of intraocular inflammatory cell response and each of clinical features, timing of vitrectomy, and outcome.

\section{Methods}

We evaluated prospectively 22 consecutive eyes with retained intravitreal lens fragments after phacoemulsification over a period of 9 months from October 1995. All patients were referred to the vitreoretinal unit at Moorfields Eye Hospital for vitrectomy and removal of the retained lens material in the posterior segment. Ocular examination included recording of visual acuity, applanation tonometry, assessment of corneal clarity and degree of uveitis, fundal examination, and an estimation of the amount and nature of the retained lens fragments. Intraocular pressure was considered raised when above $21 \mathrm{~mm} \mathrm{Hg}$ or if regular antiglaucoma medication was required. Corneal oedema was considered significant when both stromal and epithelial oedema were present and anterior uveitis was graded by the number of cells in the anterior chamber $(1+=$ minimum cells and $4+=$ marked cells with hypopyon).

Vitrectomy was performed when there was persistent uveitis and/or raised intraocular pressure (IOP) or when the amount of intravitreal lens material was considered to be great enough to produce chronic inflammation. Removal of lens material was accomplished using a standard three port pars plana vitrectomy technique with either ultrasonic fragmentation or mechanical crushing of lens fragments by the using the illuminated probe against the vitreous cutter port.

Undiluted aqueous $(0.3 \mathrm{ml})$ and vitreous $(0.5 \mathrm{ml})$ samples were obtained and Cytospin preparation made. Volumes of $100 \mathrm{ml}$ of 


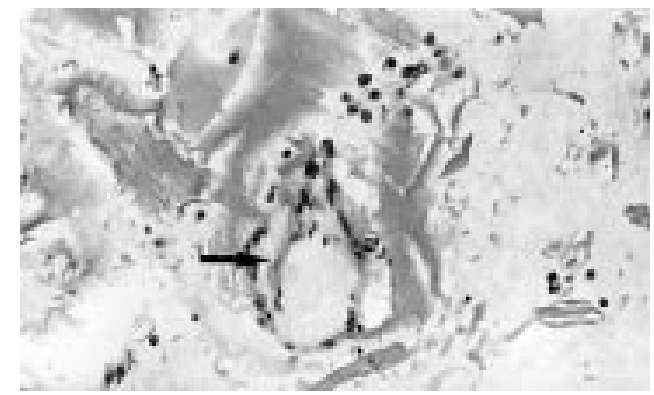

Figure 1 Mixed inflammatory cells, many heavily pigmented clustered around retained intravitreal lens fibres. Note the early fibrocellular membrane (arrow). Haematoxylin and eosin, $\times 150$.

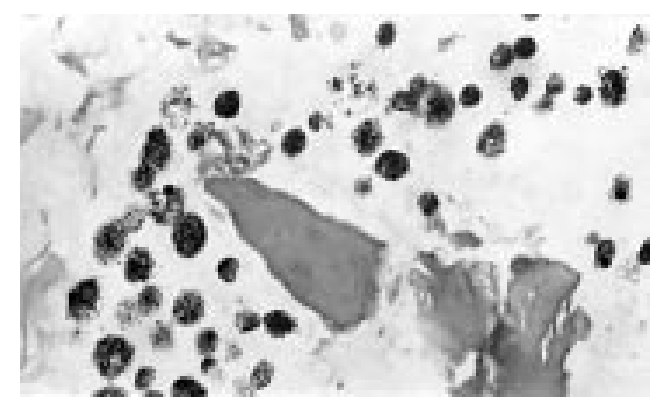

Figure 2 Pigment containing macrophages surrounding lens fragments. Haematoxylin and eosin, $\times 300$.

vitreous washings were collected for Cytoblock preparation. Sections and cytology preparations were stained with haematoxylin and eosin. The absolute numbers of the different cell types were counted in three adjacent high power microscope fields $(\times 60$ objective, field area $=0.099 \mathrm{~mm}^{2}$ ) from Cytoblock sections of vitreous washings from the area where cells were most abundant. Slides were evaluated masked to clinical details. The cell counts for each patient were then averaged and clinical and pathological findings were correlated.

To assess whether there was any association between the intensity of cellular response and each of the factors under consideration, we used the Wilcoxon rank sum test, a $p$ value less than 0.05 being considered statistically significant.

\section{Results}

CLINICAL

One patient underwent pars plana vitrectomy at the time of cataract surgery and lens fragment dislocation so that the pre-vitrectomy visual acuity and IOP were not available. At initial examination the remaining 21 patients had best corrected visual acuity of worse than 6/24 with $11(52.4 \%$ ) 6/60 or worse. Nineteen out of 21 patients $(90 \%)$ had increased IOP before vitrectomy. Mean pre-vitrectomy IOP was $32 \mathrm{~mm} \mathrm{Hg}$ with a range from $13-48 \mathrm{~mm}$

Table 1 Visual acuity (VA) results

\begin{tabular}{lllllll}
\hline & & \multicolumn{2}{l}{ Total cell count $\left(\right.$ cells $\left./ \mathrm{mm}^{2}\right)$} & & \multicolumn{2}{l}{ Interval to vitrectomy (days) } \\
\cline { 3 - 3 } Post op VA & No of cases & Median & $I^{\star}$ range & & Median & IQ range \\
\hline 6/12 and better & 13 & 40 & $(17,91)$ & & 5 & $(2,9)$ \\
6/18 and worse & $9 \dagger$ & 119 & $(104,199)$ & & 29.5 & $(24,48)$ \\
Rank sum p value & & 0.02 & & & 0.002 & \\
\hline
\end{tabular}

${ }^{\star} \mathrm{IQ}=$ interquartile. $†$ Counts given for the six patients without pre-existing cause of poor vision.
$\mathrm{Hg}$. Of the two patients with normal IOP, one had pre-existing glaucoma with previous trabeculectomy unrelated to the cataract surgery. Significant corneal oedema was present before vitrectomy in six patients and uveitis $(>2+$ cells) in 18 patients. Follow up time ranged from 3 to 9 months. With a minimum of 3 months' follow up, visual acuity improved after vitrectomy in all patients. Final acuity was $6 / 12$ or better in 13 of 22 eyes (59\%). Of the remaining nine, one had a choroidal haemorrhage during the cataract operation and subsequent retinal detachment, two had pre-existing maculopathy, and six had persistent glaucoma.

\section{HISTOPATHOLOGY}

Macrophages, lymphocytes, and neutrophils were identified in both Cytospin and Cytoblock preparations. Both aqueous and undiluted vitreous specimens had very low inflammatory cell yields compared with the vitreous washings; hence, the cell counts were taken from vitreous washing specimens. Macrophages were the predominant cell type. The cells were notably clustered around lens fibres (Fig 1) and some macrophages were heavily pigmented (Fig 2); this was considered to be phagocytosed iris pigment. Rarely, early fibrocellular membrane formation was seen in relation to the lens fragments and inflammatory cells (Fig 1).

\section{CLINICOPATHOLOGICAL ASSOCIATION}

\section{Visual outcome}

Excluding the cases with a pre-existing cause for poor vision, the average macrophage count in the remaining six patients who had an ultimate visual acuity of $6 / 18$ or less was significantly higher at a median of 113 cells per $\mathrm{mm}^{2}$ (interquartile range 98, 192) compared with $34(13,81)$ cells per $\mathrm{mm}^{2}$ in patients with good final visual acuity $(\mathrm{p}=0.02)$. Median total cell count was also greater at 119 (104, 199) cells per $\mathrm{mm}^{2}$ compared with $40(17,91)$ $(p=0.02)$. The patients with final vision of better than $6 / 12$ had a median interval of 5 days before vitrectomy compared with 29.5 days in patients who had final visual outcome of $6 / 18$ or worse $(p=0.002)$ (Table 1$)$.

\section{Intraocular pressure}

The IOP remained elevated in nine patients after vitrectomy. The median (interquartile range) macrophage and total cell counts in these patients were $98(74,104)$ and 104 (91, 114) cells per $\mathrm{mm}^{2}$ respectively. These values were more than the cell counts $(20(7,27)$ and $37(17,67))$ in patients where the IOP returned to normal, although not statistically significantly so $(p=0.12$ and $p=0.17$, respectively) perhaps because of the comparatively small numbers in the study. The timing of vitrectomy after cataract surgery in these nine patients was significantly later. The median number of days before removal of retained lens material was 29 compared with five in the remaining 13 patients with normalised IOP ( $p$ $=0.008)($ Table 2$)$. 
Table 2 Intraocular pressure (IOP) results

\begin{tabular}{|c|c|c|c|c|c|}
\hline \multirow[b]{2}{*}{ Postop IOP } & \multirow[b]{2}{*}{ No of cases } & \multicolumn{2}{|c|}{ Total cell count $\left(\right.$ cells $\left./ \mathrm{mm}^{2}\right)$} & \multicolumn{2}{|c|}{ Interval to vitrectomy (days) } \\
\hline & & Median & $I Q^{\star}$ range & Median & IQ range \\
\hline $\begin{array}{l}\text { High IOP } \\
\text { Normal IOP } \\
\text { Rank Sum p value }\end{array}$ & $\begin{array}{l}9 \\
13\end{array}$ & $\begin{array}{l}104 \\
37 \\
0.17\end{array}$ & $(17,67)$ & $\begin{array}{l}29 \\
5 \\
0.008\end{array}$ & $\begin{array}{l}(11,30) \\
(2,9)\end{array}$ \\
\hline
\end{tabular}

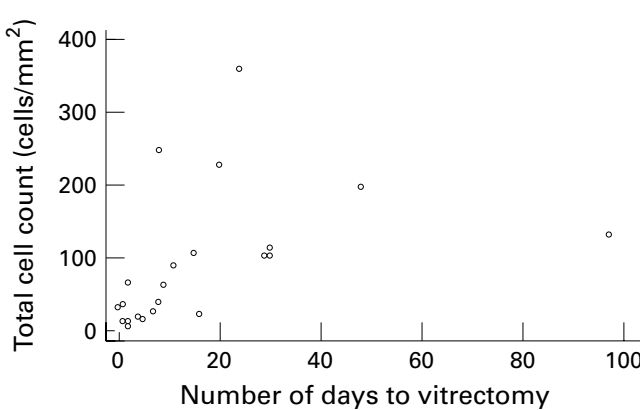

Figure 3 Scatter plot of total cell count against time of vitrectomy.

Table 3 Timing of vitrectomy

\begin{tabular}{llll}
\hline & & \multicolumn{2}{l}{ Total cell count $\left(\right.$ cells/mm $\left.\mathrm{mm}^{2}\right)$} \\
\cline { 3 - 4 } Timing of vitrectomy & No of cases & Median & IQ range \\
\hline Early (1 week or less) & 9 & 20 & $(13,34)$ \\
Late (more than 1 week) & 13 & 108 & $(91,199)$ \\
Rank sum p value & & $<0.001$ &
\end{tabular}

Timing of vitrectomy

The interval between complicated phacoemulsification and vitrectomy with lens fragment removal ranged from immediate intervention to 97 days. Figure 3 is a scatter plot of the total cell count against the time of vitrectomy and illustrates a general increase in cell count with time. One patient underwent vitrectomy at the time of cataract surgery and eight further patients within 7 days of cataract surgery $(41 \%)$. For the purpose of statistical evaluation, these were considered "early" vitrectomies. The remaining 13 patients $(59 \%)$ had vitrectomy more than 1 week after cataract surgery and had significantly greater cell counts than patients with early lens fragment removal. The macrophage and total cell counts were $101(74,192)$ and $108(91,199)$ (late vitrectomy cases) compared with $20(7,27)$ and $20(13,34)$ (early vitrectomy cases) cells $\mathrm{mm}^{2}$ respectively $(\mathrm{p}<0.001)$ (Table 3$)$. There was no correlation between significant corneal oedema or anterior uveitis and the intensity of cellular response.

\section{Discussion}

Dislocation of lens fragments into the vitreous during phacoemulsification is an uncommon event. However, with wider use of the technique this complication has been increasing in frequency. ${ }^{11-13}$ Unencapsulated lens material is known to induce a variable degree of intraocular inflammation often associated with a number of potential complications. ${ }^{1-9}$

Some success has been reported with conservative treatment in eyes with relatively little retained lens matter and minimal symptoms. ${ }^{314}$ However, Gilliand et $a l^{3}$ also reported that even a minimal amount of lens material can cause persistent inflammation and other sight threatening complications. The removal of the lens fragments by vitrectomy seems logical because limiting the inflammatory reaction should result in fewer long term sequelae and a better ultimate visual result. Vitrectomy has been reported to be effective and visual outcome has often been favourable although it does involve the risks of further surgical intervention. ${ }^{2-6}$

The ideal timing of vitreous surgery and lens fragment removal after cataract surgery is uncertain. A recent study has suggested that visual prognosis appears to be better if vitrectomy is done within 1 week $^{6}$ although a number of studies have found no correlation between visual outcome and the timing of vitrectomy. ${ }^{2}{ }^{5}$ 15-17 $^{17}$ Previous studies are, however, retrospective and may well be biased by a tendency to operate early on eyes with greater volumes of retained lens fragments, a more marked early inflammatory response, or raised intraocular pressure at an earlier stage. It is notable that one study found an increased incidence of retinal complications associated with "early" vitrectomy. ${ }^{18}$

In this study we assessed the inflammatory response by counting the peak cell density in vitreous specimens. The counts were made on specimens of vitreous washings which consistently gave a high yield of cells, perhaps because they contained the largest amounts of lens material where most inflammatory cells were aggregated.

Our study demonstrates an ongoing and progressive inflammatory cell response in eyes with retained intravitreal lens fragments. We found a significant correlation between the number of inflammatory cells in the vitreous and the timing of vitrectomy. There was also a positive correlation between the degree of cellular response and the occurrence of persistent glaucoma and a negative correlation with final visual outcome.

Early vitrectomy (within 1 week of cataract surgery) was associated with significantly lower inflammatory cell counts in the vitreous compared with eyes vitrectomised later. A more severe inflammatory reaction was noted after 1 week. The lack of intravitreal inflammatory cell response in eyes which we operated on early supports the view that prompt removal of retained lens material within 1 week reduces subsequent intraocular inflammation and its sequelae.

The relative contribution of lens nucleus and lens cortex to inflammation in the eye is uncertain. We were unable to ascertain accurately the nature of the retained lens material and to differentiate between nucleus or cortex, especially in the cases that were referred to us more than a month after cataract surgery. Moreover, it is likely that there was both nuclear and cortical material, albeit in different amounts, in most eyes. The volume of lens material was also difficult to assess when there were multiple fragments dispersed in the vitreous and this could not be correlated with the cellular response. 
According to Blodi et $a l^{2}$ the risk of chronic glaucoma on long term follow up was increased if vitrectomy was performed more than 3 weeks after cataract surgery. This relation was not found by Gilliand et $a l^{3}$ and Kim et al. ${ }^{5}$ In our study we found that the nine patients with persistently raised IOP after lens fragment removal had mean cell counts which were greater than in eyes with normalised IOP. Vitrectomy was also performed much later in these nine eyes compared with an average of less than 1 week in the others.

Visual acuity improved in all our patients after vitrectomy. The patients with better than $6 / 12$ vision had significantly less inflammatory cell counts and earlier vitrectomy. These results further emphasise the benefits of early vitrectomy within 1 week of complicated cataract surgery.

1 Irvine WD, Flynn HW Jr, Murray TG, et al. Retained lens fragments after phacoemulsification manifesting as marked intraocular inflammation with hypopyon. Am f Ophthalmol 1992;114:610-14.

2 Blodi BA, Flynn HW Jr, Blodi CF, et al. Retained nuclei after cataract surgery. Ophthalmology 1992;99:41-4.

3 Gilliand GD, Hutton WL, Fuller DG. Retained intravitreal lens fragments after cataract surgery. Ophthalmology 1992; 99:1263-9
4 Lambrou FH Jr, Stewart MW. Management of dislocated lens fragments during phacoemulsification. Ophthalmology lens fragments durin

5 Kim JE, Flynn HW Jr, Smiddy WE, et al. Retained lens fragments after phacoemulsification. Ophthalmology 1994;101: 1827-32

6 Tommila P, Immonen I. Dislocated nucleur fragments after cataract surgery. Eye 1995;9:437-41.

7 Hutton WL, Snyder WB, Vaiser A. Management of surgically dislocated intravitreal lens fragments by pars plana vitrectomy. Ophthalmology 1978;85:176-89.

8 Wolter JR. Foreign body reaction to firm nucleus lens substance. Ophthalmic Surg 1983;14:135-8.

9 Filipe JC, Palmares J, Delago L, et al. Phacolytic glaucoma and lens-induced uveitis. Int Ophthalmol 1993;17:289-93.

10 Franks WA, Limb GA, Stanford MR, ot al. Cytokines in human intraocular inflammation. Curr Eye Res 1992; 11(Suppl): 187-91.

11 Emery JM, Wilhelmus KA, Rosenbery S. Complications of phacoemulsification. Ophthalmology 1978;85:141-50.

12 Fung WE. Phacoemulsification. Ophthalmology 1978;85:45-

13 Jaffe NS, Jaffe MS, Gaffe GF. Cataract surgery and its complications. 5th ed. St Louis: CV Mosby, 1990:277

14 Fastenburg DM, Schwartz PL, Shakin JL, et al. Management of dislocated nucleur fragments after phacoemulsification. Am F Ophthalmol 1991;112:535-9.

15 Margerio RR, Margerio AR, Pendergast SD, et al. Vitrectomy for retained lens fragments after phacoemulsification. Ophthalmology 1997;104:1426-32.

16 Vilar NF, Flynn HW Jr, Smiddy WE, et al. Removal of retained lens fragments after phacoemulsification reverses secondary glaucoma and restores visual acuity. Ophthalmolsecondary glaucoma and
ogy 1997;104:787-91.

17 Borne MJ, Tasman W, Regillo C, et al. Outcomes of vitrectomy for retained lens fragments. Ophthalmology 1996;103: 971-6.

18 Wong D, Briggs MC, Hickey-Dwyer MU, et al. Removal of lens fragments from the vitreous cavity. Eye 1997;11:37-4. 